\title{
ZS Research Square \\ Incidence of Ocular, Adnexal and Orbital Trauma at Different Tertiary Care Centers of Karachi.
}

\author{
Nazia Qidwai ( $\square$ nazia_qidwai@hotmail.com )

\section{Saba Alkhairy} \\ Dow International Medical College \\ Nausheen Masood \\ Jinnah Post Graduate Medical Centre
}

Isra Postgraduate Institute of Ophthalmology https://orcid.org/0000-0003-0883-8900

\section{Research Article}

Keywords: Ocular trauma, workplace, chemical, road traffic accidents, COVID 19

Posted Date: August 6th, 2021

DOI: https://doi.org/10.21203/rs.3.rs-775923/v1

License: (1) This work is licensed under a Creative Commons Attribution 4.0 International License. Read Full License 


\section{Abstract}

Purpose:

To assess the incidence of ocular trauma resulting from various inciting agents presenting at three large centers of Karachi, Pakistan.

Method:

Patients with ocular trauma were recruited at the three centers over a period of three months, in this study. Any other ocular disease was excluded. After informed consent, history and examination was done. A proforma was filled for every patient. The various inciting agents were identified and incidence of the different types of ocular damage found. Trauma scoring was also done according to the Ocular Trauma Score.

Results:

A total of 343 patients with trauma presenting at different tertiary centres including DIMC 38 (11\%), JPMC 150 (44\%) and IPIO 155 (45\%). Male predominance was found overall. Patients presented with different forms of injuries at the three centers. Commonest presentation at IPIO was of keratitis, at JPMC of road traffic accidents and at DIMC of corneal and conjunctival foreign body impaction. Most of the patients fell at grade 5 of Ocular Trauma Score.

Conclusion:

This study showed that the type of inciting agents were different at the three centers respective to their location, surrounding workplaces and the authority of the hospital to attend to medicolegal cases.

\section{Introduction}

Trauma to the eye is a vital and potentially avoidable cause of ocular morbidity. It can severely damage the eye and may lead to blindness. The number of people affected by eye injuries is over half a million globally each year.[1]

The most common type of injuries are foreign bodies (35\%), open wounds (25\%) and contusions (25\%) followed by burns which account for $15 \%$ of the injuries. $90 \%$ of these injuries could have been protected by proper eye wear.[2]

Ocular injuries pose a great threat to the visual acuity and can not only lead to significant visual disability but also result in time lost from work, medication and sometimes surgical expense and a great cause of anxiety for the patient. In spite of this, education and public awareness regarding prevention of eye Injuries and their immediate management have been an area of neglect.

A study conducted in the twin cities of Punjab ranged the prevalence of occupational injuries to almost $30 \%$ in welders working primarily in the automobile sectors.[6] Safety measures are not implemented while working as usage of proper glasses/goggles/shields can reduce occupational hazards to a considerable degree.

We conducted a multicentered study which included patients presenting to three major tertiary care centers located in Karachi with complaint of ocular trauma namely, Isra Postgraduate Institute of Ophthalmology (IPIO), Jinnah Postgraduate Medical Centre (JPMC) and Dow International Medical College (DIMC). The details regarding the mode of injuries, time elapsed since injury ocular findings such as visual acuity, lacerations, presence of foreign bodies, 
globe rupture etc. were meticulously recorded in all centers to determine the ocular trauma score and hence to analyze the common presentation of ocular trauma and its associated morbidity.

The ocular trauma score is a standard method to predict the visual outcomes in patients affected with trauma to the eye. It was developed by Kuhn in 2002. The OTS takes into account certain variables (visual acuity, rupture, endophthalmitis, perforating injury, retinal detachment, and afferent pupillary defect) at presentation. The possible final visual acuities (NLP, LP/HM, 1/200 - 19/200, 20/200 - 20/50, and $\geq 20 / 40$ ) in the OTS categories (1 to 5) was calculated. $[3,4,5]$

To the best of our knowledge we do not know of any similar local prospective multicentered study that has been conducted in Pakistan.

There is a dire need to highlight the common forms of ocular trauma that present to the emergency and the methods that can be taken to prevent them and to administer timely treatment so as to reduce the associated ocular morbidity.

\section{Material And Methods}

It is a prospective cross sectional study conducted in the largest metropolis of Pakistan looking after a population of over 20 million. Three largest ophthalmic centers of Karachi collaborated to contribute the data of three months, named Isra Post-graduate Institute of Ophthalmology (IPIO), Jinnah Postgraduate Medical Centre (JPMC), and Dow International Medical College (DIMC).

In this multicentered study, conducted from August 12020 to October 31 2020, a total of 343 patients were evaluated out of which, 150 patients were from Jinnah Postgraduate Medical Center, 155 patients from Isra Postgraduate Institute of Ophthalmology and 38 patients were from Dow International Medical College. Approval from the ethical committee was obtained and informed consent was taken from all the patients beforehand. A sample of 343 was calculated by Raosoft sample calculator by taking pooled prevalence of ocular injuries is $38.27 \%$ (34), keeping $95 \%$ confidence interval and $5 \%$ margin of error.

We drafted a customized proforma to record data for this study, which contains information of demographics including, history and relevant examination details. All patients were informed and explained about the process. These proformas were filled up by a single doctor in their respective institute (3 doctors from 3 hospitals). Majority of the patients included in this study reported in the Accidents and Emergency department of the hospital, from where they were referred to Eye care units of the respective institute. Every individual was requested for a brief history and assessed for visual acuity, ocular examination for anterior and posterior segment, along with orbital and adnexal examination. Gross general physical examination was also performed, and referrals to the relevant department were sent in cases where it was necessary. Consequently, Ocular Trauma Scores (OTS) were calculated of every individual included in data, which has 5 factors for visual assessment. (Fig. 1.)

Patients' inclusion in the study is based on history and signs of recent trauma to eyelid, adnexa or orbit. Patients of any age were included. The exclusion criteria consisted of any other cause for the ocular damage apart from trauma.

Data was analyzed by using SPSS version 22.0. Mean \pm S.D was calculated for continuous variables such as age. 
Frequencies and percentages were calculated for categorical variables like gender, visual acuity, mode of injuries and sign and symptoms. Doughnut chart was made to present no. of patients at each center while multiple bar chart was made to see the trauma scoring at each center.

\section{Statistical Analysis:}

Data was analyzed by using SPSS version 22.0. Mean \pm S.D was calculated for continuous variables such as age. Frequencies and percentages were calculated for categorical variables like gender, visual acuity, mode of injuries and sign and symptoms. Doughnut chart was made to present no. of patients at each center while multiple bar chart was made to see the trauma scoring at each center.

\section{Results}

A total of 343 patients with trauma presenting at different tertiary centers including DIMC 38 (11\%), JPMC 150 (44\%) and IPIO 155 (45\%). (Fig. 2). The demographic details of these patients is briefly describe in Table I.

At DIMC, 20 (52.63\%) cases came due to different kinds of accidents by bicycle stand, wood, door etc. Second commonest way of injury was at workplace as 16 (42.11\%) patients got injured during welding and grinding stone. At JPMC, assault was the most frequent way of injury as 48 (31.75\%) patients suffered due to various kind of attacks like acid splash, hit by steel rod, punch, scissors and stone etc. Road traffic accidents was the second common way of injury as the 29 (19.21\%) patients reported due to accidents on road. Twenty-five (16.56\%) cases were reported due to hit by blunt objects like Cracker, tire burst and ball etc. At IPIO, 100 (64.52\%) cases were reported due to different accidental exposures as patients got hit by Tennis ball, glass, knife, pipe and scissor etc. Second commonest cause of injury was due to working in construction sector as 11 (7.10\%) patients were hit by stone. Details are shown in Table II.

Patients visual acuity was also checked at the time of presentation. At DIMC, most of the patients came with good vision (6/6-6/18), Similarly at JPMC, 93 (62\%) patients had a good vision at the time of presentation. At IPIO, 82 $(52.90 \%)$ patients came with good vision while $44(28.38 \%)$ patients came with poor vision $(<6 / 60)$. (Table - III)

Trauma scoring was also measured on the basis OTS chart (Koh et al) at each center. At DIMC, 18 (47.37\%) patients came with OTS score of 5 and 13 (34.21\%) had an OTS score of 4. Similarly, at JPMC, most of the patients, 86 (57.33\%) patients had an OTS score 5 while $37(24.67 \%)$ had a score of 4 . Similar pattern was noticed at IPIO as 57 $(36.77 \%)$ patients had an OTS score of 5 whereas $36(23.23 \%)$ patients had a score of 4 . There are also 5 (3.23\%) non-verbal kids as well. (Fig. 3)

Patients came with numerous signs and symptoms at presentation. At DIMC, commonest sign was Lid swelling as $10(26.32 \%)$, those related to cornea 10 (26.32\%) and subconjunctival hemorrhages 4 (10.53\%). At JPMC, 29 (16.20\%) patients came with a sign of lid tear, 17 (9.50\%) presented with corneal ulcer and $13(7.26 \%)$ came with periorbital swelling. Similarly, at IPIO most of the signs were related to Subconjunctival hemorrhage as 35 (13.21\%), others 25 (9.43\%) were related corneal foreign body. (Table -IV)

\section{Discussion}

Ocular trauma is a major problem faced in Karachi which results from disobeyance to laws, weak security status, domestic violence, lack of education and awareness and a care-free attitude towards handling of hazardous objects. These could, occur at workplace, at home including fall, door injuries and accidental injuries.; be related to road 
traffic accidents, assault and to leisure activities, fireworks, blast injuries etc. Domestic accidents and assaults nearly make one third of injuries. $[2,7,8]$ Apart from the various eye disorders causing blindness as seen in a US eye disease statistics survey, ocular trauma is also a big cause. [9]

Various studies have shown varied orders of incidence of trauma according to the socioeconomic and cultural circumstances in the site of event. Zakrzewski et al showed that workplace incidents were the commonest, followed by domestic causes. [10] In the study of Ying Qi work-related injuries accounted for 31.5\% followed by household injuries (27.4\%), firework injuries (24.5\%), electric bicycles (15.1\%), animal related injuries (8.4\%) and Sports injuries (7.3\%). [11]

Many a times the patient, the attendant or a quack manage the injury initially but when the trauma is severe or gets complicated, it is then brought to an eye clinic. The state of hospitality and medical supplies of eye clinics in rural and urban areas is another detrimental factor. Patients suffering ocular trauma in rural areas do not either find a qualified optometrist or ophthalmologist or do not receive appropriate management from the available medical personnel. Factors which formulate the final visual and structural outcome include, mode, velocity severity and site of injury, duration spent since trauma, age of patients, co-occurrence of any systemic illnesses, primary or secondary infections, duration of exposure to the traumatizing object and the duration spent till commencement of appropriate treatment. [12]

Our study was based on data collection of ocular trauma patients who presented at three large tertiary care hospitals of Karachi; the Isra Post-graduate Institute of Ophthalmology (IPIO), the Jinnah Post-graduate Medical Centre (JPMC) and the Dow International Medical College and Hospital (DIMC).

The number of patients at JPMC and IPIO were nearly the same. Fewer patients presented at DIMC versus the other two tertiary care institutions. Possible reasons could be that it is located considerably away from the city center and is not easily approachable to the vast majority of population. Services offered are paid hence non-affording patients do not visit this center. The eye department is fairly new with limited faculty members as compared to the other two institutes and is still in its development stages.

Males outnumbered females in a10ll our three centers because they still work in bigger numbers outside than females. Many national and international studies have shown this male preponderance to be $83.87 \%, 84.2 \%, 81.6 \%$. $[12,13,14]$ In a large study conducted by Ying Qi et al, the male to female ratio was 2.8:1. [11]

In our study the commonest age of patients lied between 20-50 years which is the prime working age in Pakistan. Adolescents are taken out of school and put to work at a younger age. Being at a vulnerable age with lack of education, financial instability and social ill-development they are at an increased risk of injuries. The lower limit of age of working females is decreasing rapidly as more girl kids now mainly working in the service sector start working at a yet younger age.

Various studies showed the commonest age of presentation to be between 45-59 years, 17 and 39 years and 1835 years $[11,12,13,15]$.

It was noted that incidence of the different modes of injury, were different at the three centers. At JPMC, adult cases of Road Traffic Accident and assault topped the list. JPMC is the largest tertiary care center built on Sharea Faisal which is a main street connecting to multiple areas of Karachi. Multidisciplinary management is effectively possible here for patients who present with multiple injuries as the hospital has all medical and surgical departments. Medicolegal cases are accepted here. 44 cases presented with injury from assault and 29 of RTA. This mainly 
reflects the high frustration level of society, disobedience of traffic rules and the prevalent fearless attitude to indulge in assault and encounter, readily.

In various studies the incidence of RTA related injuries was $24.2 \%, 25.2 \%$ cases and $20.5 \%$ patients. $[11,13,14]$ In the west, incidence of RTA and assault are also considered to be associated with alcoholism and substance use. [16]

14 cases at JPMC presented with chemical injury of which 4 occurred at workplace, 4 as a result of assault and 6 related to accidental exposure to agents like sanitizer, thinner, perfume, caustic soda and commonly available adhesives like Elfy. The over the counter availability of acids, alkalis and kerosene oil has consistently kept number of cases of assault from chemical injury, high, mostly in young and middle-aged ladies. Cases of sanitizer splash into eyes rose during this study's duration because of its increased use during this Corona virus pandemic.

Koh et al showed that workplace presents the greatest risk of chemical injuries. [17] Alkali is a commoner cause than acid in workplace setting. These include ammonia, lye (sodium hydroxide), potassium hydroxide, magnesium hydroxide, and lime which are found in fertilizers, refrigerants, and cleaning solutions drain cleaners. Lime is the commonest cause of workplace chemical injuries overall and is found in plaster, mortar, cement, and whitewash. [18] In the study of Quesada et al ocular chemical burns were the second most common workplace eye injury with $68.54 \%$ of men and $31.45 \%$ females getting affected. [19] The largest proportion of chemical eye injuries were seen in women in cleaning and kitchen jobs which results from splashing and spraying of liquids [20]. The cause has been attributed to, limited training. [21]

At IPIO cases of corneal injury and keratitis resulting from foreign body exposure, presented the most. This is mainly because this center is located in the out skirts of Karachi surrounded by villages and farms. Whilst travelling through dusty lands and working in farms, they get exposed to dust, stones and vegetative matter. Industrial workers, vehicle mechanics and welders fell next and reported exposure to metallic particles, wires or rods. Blunt objects were found to be the commonest causative agent. They often work without abiding by to any appropriate handling measures. In study of Ying Qi et al 21.4\% cases resulted from metals, knives and scissors. Construction sector workers reported with exposure to stones, sand and pebbles. Chemical injuries reported from exposure to bleach, used for cleaning in homes and from acid use, resulting from car or UPS (Uninterruptable power supply) battery explosion. Ying Qi showed that $51.9 \%$ of the cases were farmers and workers.[11] Tan HH's study revealed that $53 \%$ of the workers included cleaners, workersr and technicians. [22]. Bhupally et al showed chemical injuries to be the second commonest (13\%) in their study. [12]

At DIMC cases of accidental injury resulting from various foreign bodies followed by that of welding and grinding ranked high. There are many workplaces of welders and iron mongers in the vicinity. Quesada et al's study showed foreign bodies to be the top most cause of ocular injury (43.42\%). $29.4 \%$ cases were affected with metallic foreign body in the study of Khaqan et al.[19]

In the study of Bhupally et al the commonest mode of ocular trauma was blunt trauma (77.6\%) [12]

Children overall suffered trauma with varied objects easily accessible at home and on streets. During the covid 19 pandemic, kids were mostly out of school and staying at home. This increased their chance to get exposed to various inciting agents like rooster's and bird's beaks, matchsticks, adhesives (elfy), pencils, knife, screw driver, scissors etc. Increased use of gadgets also impacted through the cartoons shown on the various kids' channels which show trauma as fun. In our study we got most kids of age 7 years. This reflects lack of parental supervision. Kids are freely allowed to play on streets which further predisposes them to various forms of trauma. Child labour in 
Pakistan also exposes children to hazardous agents.[23] In the study of Malik I.Q. 70\% casaes occured in the age group less than 10 years. The male: female ratio was 1.6:1 which incremented to $10: 1$ after age 10 years. [15] In the study by Khaqan H. A. 28.8\% patients were less than 10 years old and the mean age of children was 8.09 years. [14] In the study of Ying Qi patients aged younger than 2y comprised 5.3\%.[11] Commonest causes of ocular trauma have been found to be house-hold items, RTA and physical abuse in various studies. [24, 25]

Commonest sign at presentation at DIMC were impacted foreign body, at JPMC it was lid and corneal tears, followed by cases of chemical trauma. At IPIO Corneal foreign body, Keratitis, Corneal tear, Corneal opacity, Iris prolapse, Pupillary irregularity, Hyphema and Cataract were found in decreasing order. Since children made a large part of the sample size, Traumatic Endophthalmitis was found in 15 cases. These signs were clearly related to the type of inciting trauma.

Other studies showed nearly similar results. In one study Open Globe Injuries occurred in 53.4\%. [13] In yet another study Intraocular foreign bodies (IOFB) were found in 15\%, corneal tears in 75\%, corneo-scleral tears in $24 \%$, cataract formation in 61.6\% and retinal detachment occurred in 9.81\%.[15] In the study of Ying Qi the commonest signs were traumatic cataract $(25.0 \%)$, endophthalmitis (16.8\%), intraocular foreign bodies (16.6\%), retinal detachment (15.0\%) [11]

Worldwide, however, due to the ongoing pandemic, an overall decrease in the incidence of trauma was reported. Christey et al. reported a $43 \%$ reduction in injury related hospitalization. [26] Pellegrini et al reported $68.4 \%$ reduction in the number of eye trauma cases during the first month of the pandemic as compared to the same period of previous year. They found that a massive decrease occured in sport related ocular injuries (from 6.5-0.9\%) [27, 32]. An increase in the household related ocular injuries was however, observed, however. [28, 29, 33]

Most of the patients from all 3 centers fell at grade 5 of the OTS and their Visual acuity ranged mostly between $6 / 6$ and 6/18. It was between PL + and 6/60 in the study by Khaqan et al. This co-related with the high number of RTA cases. [14]

According to an international survey 200,000 open-globe injuries occur annually resulting in 1.6 million blind, 2.3 million bilaterally and 19 million unilaterally. [31] Ocular trauma results in inability to continue jobs and chores at home and workplace. It increases financial and physical burden on the patient and attendants. [10, 30]. As seen by Quesada et al 6 patients suffered permanently partial disability. [19] Quesada et al found that the total cost of the initial emergency consultation, follow up consultations, nursing appointments, consultations with the ophthalmologist, medical transport and medication and treatment costs, were very high. [19]

We recommend as in coherence with other studies that at workplace Personal Protective Equipment (PPE) must be provided by the authorities and religiously used by the workers. Laws be made and their abidance made mandatory. In our part of the world taking care of traffic rules and by enacting punishment for illegal acts the cases of RTA and assault especially of domestic violence and child abuse would immensely reduce. Child labor and over the counter availability of chemicals be checked sternly. The care-free attitude towards handling of sharps at home be addressed via awareness sessions including pictorials and videos showing the possible consequences of ocular injuries via various common house-hold objects. [19, 33]

\section{Declarations}

There are no conflicts of interest. All data has been provided as available in the patient files. 


\section{References}

1. Negrel AD, Thylefors B. The global impact of eye injuries. Ophthalmic Epidemiol 1998; 5: 143-69.

2. American Academy of Ophthalmology. Eye health statistics. Available at: http://www.aao.org/newsroom/eyehealth-statistics.

3. Kuhn F, Maisiak R, Mann L, Mester V, Morris R, Witherspoon CD. The ocular trauma score (OTS). Ophthalmol Clin North Am. 2002 Jun;15(2):163-5, vi. PMID: 12229231.

4. Kuhn F, Morris R, Witherspoon CD. Birmingham eye trauma terminology (BETT): terminology and classification of mechanical eye injuries. Ophthalmol Clin North Am. 2002 Jun;15(2):139-43, v. PMID: 12229228.

5. Scott R. The ocular trauma score. Community Eye Health. 2015;28(91):44-5. PMID: 2698930.

6. Shaikh MA. Hazard perception and occupational injuries in the welders and lathe machine operators of Rawalpindi and Islamabad. J Pak Mer Assoc 2001;51(2):71-4.

7. Shiuey E. J., Kolomeyer, A. M, Kolomeyer N. N. Assessment of Firework-Related Ocular injury in the US JAMA Ophthalmol. 2020 Jun; 138(6): 1-6.

8. Alam M., Iqbal M., Khan A., Khan S. A. Ocular injuries in blast victims J Pak Med Assoc 2012 Feb;62(2):138-42.

9. American Academy of Ophthalmology. Eye disease statistics. Available at https://www.aao.org/eye-diseasestatistics. Accessed 18 July, 2021.

10. Zakrzewski H, Chung H, Sanders E, Hanson C, Ford B. Evaluation of occupational ocular trauma: are we doing enough to promote eye safety in the workplace? Can J Ophthalmol 2017;52(4):338_42, doi:http://dx.doi.org/10.1016/ j.jcjo.2016.11.034.

11. Qi Y, Zhang FY, Peng GH, Zhu Y, Wan GM, Wang WZ, et al. Characteristics and visual outcomes of patients hospitalized for ocular trauma in central China: 2006-2011. Int J Ophthalmol. 2015;8:162-8.

12. Bhupally AK, Chigiri S.S., Swathi M., Rohini M., Shruthi T. Ocular trauma. Int J Res Med Sci. 2015 Dec;3(12):3714-3719.

13. Iqbal U, Malik I. Q., Iqbal H. Epidemiology of Ocular Trauma in a Tertiary Hospital Setting. Pak J Ophthalmol 2019, Vol. 35, No. 1.

14. Khaqan H. A., Chaudhry H. R., llyas S., Hye A.Pattern of Ocular Trauma in Tertiary Care Hospital. Pak J Ophthalmol 2017, Vol. 33, No. 2.

15. Malik I. Q., Ali Z., Rehman A., Moin M., Hussain M. Epidemiology of Penetrating Ocular Trauma. Pak J Ophthalmol 2012, Vol. 28 No. 1.

16. Jian-Wei L, Zhen-Bo H, Shu-Na W, Yu-Guang Z, Ai-Jun D Graefes The clinical characteristics of alcohol-related ocular rupture. Arch Clin Exp Ophthalmol. 2015 Aug; 253(8):1307-11.

17. Koh D-H, Lee S-G, Kim H-C. Incidence and characteristics of chemical burns. Burns 2017;43(May (3)):654_64, doi:http://dx. doi.org/10.1016/j.burns.2016.08.037.

18. https://www.aao.org/focalpointssnippetdetail.aspx?id=733e20f0-b9f1-4ad6-a3d9-94a1849d920b.

19. Quesada J. M-A., Lloves J M., Delgado D. V. Ocular chemical burns in the workplace: Epidemiological characteristics. Burns 2020 Aug;46(5):1212-1218.

20. Valdés CT, Fernandez IV. Guia para los trabajadores de sector de limpieza de edificios y locales. J Chem Inf Model 2013;1_108 E-Publishing Inc.

21. The occupational safety and health of cleaning workers. In: Brun E, editor. European agency for safety and health at work. E-Publishing Inc; 2009. p. 1 _80. 
22. Tan HH, Teo S, Tseng HC. Work-related chemical exposures presenting to an emergency department in Singapore. Occup Med (Chic III). 2014;64(2):113_9.

23. https://www.unicef.org/pakistan/child-protection-0

24. S Dulal, JB Ale, YD Sapkota. Profile of pediatric ocular trauma in mid western hilly region of Nepal. NEP J OPH 2012; 4 (1): 134-137.

25. Bailey RN, Indian RW, Zhang X, Geiss LS, Duenas MR, Saaddine JB et al. Visual impairment and eye care among older adults-five states, 2005. MMWR Morb Mortal Wkly Rep 2006; 55 (49): 1321-1325.

26. Christey G, Amey J, Campbell A, Smith A. Variation in volumes and characteristics of trauma patients admitted to a level4 lockdown for COVID-19 in New Zealand. N Z Med J. 2020;133:81-8.

27. Pellegrini M, Roda M, Geronimo ND, Lupardi E, Giannaccare G, Schiavi C. Changing trends of ocular trauma in the time of COVID-19 pandemic. Eye. 2020;34(7):1248-50. doi:10.1038/s41433-020-0933-x.

28. Wu C, Patel SN, Jenkins TL, Anthony O, Ho AC, Yonekawa. Ocular trauma during COVID-19 stay-at-home orders: a comparative cohort study. Curr Opin Ophthalmol. 2020;31(5):423-6.

29. Chang A, Schnall AH, Law R. Cleaning and disinfectant chemical exposures and temporal associations with COVID-19: National Poison data system. United States, Januaray 1, 2020- March 31 2020. MMWR Morb Mortal Wkly Rep. 2020;69:496-8.

30. Alexander V, Sindhu KN, Zechariah P, Resu AV, Nair SR, Kattula D, et al. Occupational safety measures and morbidity among welders in Vellore, Southern India. Int J Occup Environ Health 2016;22(Oct (4)):300_6.

31. Dang S. (2021) Eye injuries at work. American Academy of Ophthalmology https://www.aao.org/eyehealth/tips-prevention/injuries. Accessed 08-07-2021.

32. Organización internacional del trabajo. La seguridad y la salud en el uso de productos químicos en el trabajo, vol. 1. Revista; E-Publishing Inc; 2014. p. 1 _30.

33. Maurya R. P. Ocular trauma during COVID- 19 crisis: Trends and management. Indian J Clin Exp Ophthalmol 2020;6(4):478-479.

34. Cao H, Li L, Zhang M. Epidemiology of patients hospitalized for ocular trauma in the Chaoshan region of China, 2001-2010. PLoS One. 2012;7(10): e48377. doi: 10.1371/journal.pone.0048377. PMID: 23118997; PMCID:

PMC3485239.

\section{Tables}

Table I: Baseline Characteristics of Patients 


\begin{tabular}{llll} 
Descriptive & DIMC & JPMC & IPIO \\
\hline Male & $31(81.5 \%)$ & $115(76.6 \%)$ & $111(71.61 \%)$ \\
\hline Female & $7(18.4 \%)$ & $35(23.3 \%)$ & $44(28.3 \%)$ \\
\hline Male/Female ratio & $4.2: 1$ & $3.2: 1$ & $2.5: 1$ \\
\hline Total & $38(100 \%)$ & $150(100 \%)$ & $155(100 \%)$ \\
\hline Adults & $36(84.2 \%)$ & $115(75.3 \%)$ & $78(42.5 \%)$ \\
\hline Kids & $6(15.7 \%)$ & $35(24.6 \%)$ & $77(57.4 \%)$ \\
\hline Adults/Kids Ratio & $6: 1$ & $3.2: 1$ & $1.01: 1$ \\
\hline Mean Age Adults $(\geq 14$ yrs $)$ & $31.05 \pm 11.02$ & $30.67 \pm 13.55$ & $32.85 \pm 12.76$ \\
\hline Mean Age Kids $(<14$ yrs $)$ & $10 \pm 4.24$ & $7.1 \pm 3.58$ & $7.56 \pm 3.21$
\end{tabular}

Table II: Mode of injuries at three tertiary centres: 


\begin{tabular}{|c|c|c|c|c|c|c|c|c|}
\hline \multicolumn{3}{|c|}{ DMC } & \multicolumn{3}{|c|}{ JPMC } & \multicolumn{3}{|c|}{ IPIO } \\
\hline Mode of Injury & Count & $\%$ & Mode of Injury & Count & $\%$ & Mode of Injury & Count & $\%$ \\
\hline Road Traffic Accident & 2 & 5.26 & Raod Traffic Accident & 29 & 19.33 & Raod Traffic Accident & 6 & 3.87 \\
\hline \multicolumn{2}{|l|}{ Accidental exposure: } & & \multicolumn{2}{|l|}{ Accidental exposure: } & & \multicolumn{2}{|l|}{ Accidental exposure: } & \\
\hline Bicycle stand & 1 & 2.63 & Chemical & & & Foreign body & 32 & 20.65 \\
\hline Tree branch & 2 & 5.26 & Sanitizer spill & 1 & 0.67 & Tennis ball & 1 & 0.65 \\
\hline Door & 2 & 5.26 & Thinner splash & 1 & 0.67 & Hand & 1 & 0.65 \\
\hline Foreign body & 11 & 28.95 & Perfume & 1 & 0.67 & Fist & 2 & 1.29 \\
\hline Wood & 1 & 2.63 & Elfy & 2 & 1.33 & Elbow & 1 & 0.65 \\
\hline Frizbee & 1 & 2.63 & Caustic soda & 1 & 0.67 & finger & 1 & 0.65 \\
\hline Hand & 1 & 2.63 & Blunt objects: & & & Vegetative matter & 9 & 5.81 \\
\hline Fireworks & 1 & 2.63 & Bike handle & 1 & 0.67 & Glass & 2 & 1.29 \\
\hline Workplace injury & & & Cracker & 1 & 0.67 & Stick & 12 & 7.74 \\
\hline Grinding stone & 9 & 23.68 & Hand & 1 & 0.67 & Fall on washbasin & 3 & 1.94 \\
\hline Welding & 7 & 18.42 & Thorn & 4 & 2.67 & Door handle & 1 & 0.65 \\
\hline Sub Total & 16 & 42.11 & Foreign body & 3 & 2.00 & Rooster's beak & 1 & 0.65 \\
\hline Grand Total & 38 & 100.00 & Flame & 1 & 0.67 & Rubber band & 2 & 1.29 \\
\hline & & & Cloth & 1 & 0.67 & Goat horn & 4 & 2.58 \\
\hline & & & Tipcat (a game) & 1 & 0.67 & Knife & 2 & 1.29 \\
\hline & & & Ball & 3 & 2.00 & Bird's beak & 1 & 0.65 \\
\hline & & & \begin{tabular}{|l|} 
Nail \\
\end{tabular} & 1 & 0.67 & Pipe & 1 & 0.65 \\
\hline & & & Tree branch & 3 & 2.00 & Scissors & 1 & 0.65 \\
\hline & & & Tyre burst & 1 & 0.67 & Matchstick & 1 & 0.65 \\
\hline & & & Whe at grain & 1 & 0.67 & Wall & 1 & 0.65 \\
\hline & & & Hair band & 1 & 0.67 & Motorbike handle & 1 & 0.65 \\
\hline & & & Needle & 1 & 0.67 & Insect bite & 1 & 0.65 \\
\hline & & & Workplace: & & & Ball & 2 & 1.29 \\
\hline & & & Chemical injury & & & Toy & 1 & 0.65 \\
\hline & & & Acid spill & 3 & 2.00 & Cup & 1 & 0.65 \\
\hline & & & Lime & 1 & 0.67 & Hot water & 1 & 0.65 \\
\hline & & & Welding & 1 & 0.67 & Rope & 1 & 0.65 \\
\hline & & & Assault: & & & Pencil & 2 & 1.29 \\
\hline & & & Acid splash & 4 & 2.67 & Tree branch & 8 & 5.16 \\
\hline & & & Plastic pipe & 1 & 0.67 & Cracker & 1 & 0.65 \\
\hline & & & Broken plastic piece & 1 & 0.67 & Needle & 1 & 0.65 \\
\hline & & & plastic bottle & 1 & 0.67 & Slipper & 1 & 0.65 \\
\hline & & & Steel/ Iron rod & 2 & 1.33 & Unknown & 23 & 14.84 \\
\hline & & & Punch & 24 & 16.00 & Workplace Injury: & & \\
\hline & & & Stick & 5 & 3.33 & Welding Foreign body & 4 & 2.58 \\
\hline & & & scissors & 1 & 0.67 & \multicolumn{3}{|c|}{ Industrial and vehide mechanics: } \\
\hline & & & blunt object & 1 & 0.67 & Wire & 2 & 1.29 \\
\hline & & & knife & 2 & 1.33 & Iron/steel rod & 4 & 2.58 \\
\hline & & & stone & 6 & 4.00 & Car battery explosion & 1 & 0.65 \\
\hline & & & Unknown & 26 & 17.33 & Construction sector: & & \\
\hline & & & Falling exposure & & & Stone & 11 & 7.10 \\
\hline & & & From ladder & 4 & 2.67 & Service sector & & \\
\hline & & & From stairs & 5 & 3.33 & Chemical & & \\
\hline & & & From bike & 1 & 0.67 & Bleach & 4 & 2.58 \\
\hline & & & On glass & 2 & 1.33 & Total & 155 & 100.00 \\
\hline & & & Total & 150 & 100.00 & & & \\
\hline
\end{tabular}

Table III: Presenting VA at different Tertiary Centres. 


\begin{tabular}{|c|c|c|c|}
\hline \multicolumn{2}{|c|}{ Presenting VA at DMC } & \multicolumn{2}{|c|}{ Presenting VA at JPMC } \\
\hline VA & Count & VA & Count \\
\hline $6 / 6-6 / 18$ & 28 & $6 / 6-6 / 18$ & 93 \\
\hline$<6 / 18-6 / 60$ & 1 & $<6 / 18-6 / 60$ & 26 \\
\hline$<6 / 60$ & 9 & $<6 / 60$ & 31 \\
\hline Total & 38 & Total & 150 \\
\hline \multicolumn{4}{|c|}{ Presenting VA at IPIO } \\
\hline \multicolumn{2}{|c|}{ VA } & \multicolumn{2}{|c|}{ Count } \\
\hline \multicolumn{2}{|c|}{$6 / 6-6 / 18$} & \multicolumn{2}{|c|}{82} \\
\hline \multicolumn{2}{|c|}{$<6 / 18-6 / 60$} & \multicolumn{2}{|c|}{17} \\
\hline \multicolumn{2}{|c|}{$<6 / 60$} & \multicolumn{2}{|c|}{44} \\
\hline \multicolumn{2}{|c|}{$8 \mathrm{CPCM}$} & \multicolumn{2}{|c|}{6} \\
\hline \multicolumn{2}{|c|}{ 6/48 CARDIFF } & \multicolumn{2}{|c|}{2} \\
\hline \multicolumn{2}{|c|}{$4 \mathrm{CPCM}$} & \multicolumn{2}{|c|}{2} \\
\hline \multicolumn{2}{|c|}{ 6/15 CARDIFF } & \multicolumn{2}{|c|}{1} \\
\hline \multicolumn{2}{|c|}{ Following Light } & \multicolumn{2}{|c|}{1} \\
\hline \multicolumn{2}{|c|}{ Total } & \multicolumn{2}{|c|}{155} \\
\hline
\end{tabular}

Table: IV: Presenting signs of patients at three tertiary centres: 


\begin{tabular}{|c|c|c|c|c|c|c|c|c|}
\hline DMC & & & JPMC & & & IPIO & & \\
\hline Sign & Count & $\%$ & Signs & Count & $\%$ & Signs & Count & $\%$ \\
\hline Lid Swelling & 10 & 26.32 & Lid tear & 29 & 16.20 & $\begin{array}{l}\text { Subconj } \\
\text { hemorrhage }\end{array}$ & 35 & 13.21 \\
\hline Corneal & 10 & 26.32 & Corneal ulcer & 17 & 9.50 & $\begin{array}{l}\text { Foreign body in } \\
\text { cornea }\end{array}$ & 25 & 9.43 \\
\hline $\begin{array}{l}\text { Subconj } \\
\text { Hemorrhages }\end{array}$ & 4 & 10.53 & $\begin{array}{l}\text { Periorbital } \\
\text { swelling }\end{array}$ & 13 & 7.26 & Corneal tear & 22 & 8.30 \\
\hline Corneal Tear & 2 & 5.26 & Corneal tear & 13 & 7.26 & Keratitis & 22 & 8.30 \\
\hline Lid Tear & 2 & 5.26 & Macular edema & 11 & 6.15 & Cataract & 20 & 7.55 \\
\hline $\begin{array}{l}\text { Corneal } \\
\text { Abrasion }\end{array}$ & 1 & 2.63 & $\begin{array}{l}\text { Subconj } \\
\text { hemorrhage }\end{array}$ & 7 & 3.91 & Corneal opacity & 15 & 5.66 \\
\hline Enophthalmos & 1 & 2.63 & Corneal abrasion & 7 & 3.91 & Endophthalmitis & 15 & 5.66 \\
\hline $\begin{array}{l}\text { Mid Dilated } \\
\text { Pupil }\end{array}$ & 1 & 2.63 & Lid swelling & 6 & 3.35 & Iris prolapse & 13 & 4.91 \\
\hline RD & 1 & 2.63 & Lid abrasion & 5 & 2.79 & Pupil irregularity & 11 & 4.15 \\
\hline Optic Disc & 1 & 2.63 & Lid bruise & 5 & 2.79 & Hyphema & 8 & 3.02 \\
\hline $\begin{array}{l}\text { Vitreous } \\
\text { Hemorrhage }\end{array}$ & 1 & 2.63 & Cataract & 5 & 2.79 & Shallow AC & 7 & 2.64 \\
\hline $\begin{array}{l}\text { Commotio } \\
\text { Retinae }\end{array}$ & 1 & 2.63 & Scleral tear & 4 & 2.23 & Corneal ulcer & 6 & 2.26 \\
\hline Hyphema & 1 & 2.63 & Brow tear & 3 & 1.68 & Pyhysis & 6 & 2.26 \\
\hline Glaucoma & 1 & 2.63 & Lid ecchymosis & 3 & 1.68 & FB fornix & 6 & 2.26 \\
\hline $\begin{array}{l}\text { Red cell } \\
\text { glaucoma }\end{array}$ & 1 & 2.63 & Fungal keratitis & 3 & 1.68 & Lid tear & 5 & 1.89 \\
\hline Total & 38 & 100 & Corneal opacity & 3 & 1.68 & $\mathrm{RD}$ & 5 & 1.89 \\
\hline & & & Conjunctivitis & 3 & 1.68 & Soft eye & 5 & 1.89 \\
\hline & & & Iris prolapse & 3 & 1.68 & $\begin{array}{l}\text { Posterior } \\
\text { synechiae }\end{array}$ & 4 & 1.51 \\
\hline & & & Corneal edema & 3 & 1.68 & $\begin{array}{l}\text { Occlusion } \\
\text { papillae }\end{array}$ & 4 & 1.51 \\
\hline & & & Perforated globe & 2 & 1.12 & Lid burn & 4 & 1.51 \\
\hline & & & $\begin{array}{l}\text { Corneoscleral } \\
\text { tear }\end{array}$ & 2 & 1.12 & $\begin{array}{l}\text { Oneuritis } \\
\text { traumatic }\end{array}$ & 3 & 1.13 \\
\hline & & & RAPD & 2 & 1.12 & Iridodialysis & 3 & 1.13 \\
\hline & & & Pale disc & 2 & 1.12 & $\begin{array}{l}\text { Corneal } \\
\text { perforation }\end{array}$ & 3 & 1.13 \\
\hline & & & $\mathrm{RD}$ & 2 & 1.12 & $\begin{array}{l}\text { Anterior } \\
\text { synechiae }\end{array}$ & 2 & 0.75 \\
\hline
\end{tabular}




\begin{tabular}{|c|c|c|c|c|c|}
\hline Photo keratitis & 1 & 0.56 & $\begin{array}{l}\text { Vitreous } \\
\text { hemorrhage }\end{array}$ & 2 & 0.75 \\
\hline Endophthalmitis & 1 & 0.56 & $\begin{array}{l}\text { Band } \\
\text { keratopathy }\end{array}$ & 1 & 0.38 \\
\hline Globe rupture & 1 & 0.56 & Phacodonesis & 1 & 0.38 \\
\hline Chemosis & 1 & 0.56 & ON Atrophy & 1 & 0.38 \\
\hline CNVI palsy & 1 & 0.56 & $\begin{array}{l}\text { Paralytic } \\
\text { ectropion }\end{array}$ & 1 & 0.38 \\
\hline Iridodialysis & 1 & 0.56 & Lagophthalmos & 1 & 0.38 \\
\hline Subluxated lens & 1 & 0.56 & $\begin{array}{l}\text { Exposure } \\
\text { keratopathy }\end{array}$ & 1 & 0.38 \\
\hline APD & 1 & 0.56 & $\begin{array}{l}\text { Corneal } \\
\text { abrasion }\end{array}$ & 1 & 0.38 \\
\hline Macular scar & 1 & 0.56 & $\begin{array}{l}\text { Choroidal } \\
\text { detachment }\end{array}$ & 1 & 0.38 \\
\hline FB Corneal & 1 & 0.56 & Chemosis & 1 & 0.38 \\
\hline Hypotony & 1 & 0.56 & $\begin{array}{l}\text { Secondary } \\
\text { glaucoma }\end{array}$ & 1 & 0.38 \\
\hline$C D$ & 1 & 0.56 & PAS & 1 & 0.38 \\
\hline Limbal Ischemia & & & Scleritis with FB & 1 & 0.38 \\
\hline grade 1 & 7 & 3.91 & Symblepheron & 1 & 0.38 \\
\hline grade 2 & 3 & 1.68 & Aphakia & 1 & 0.38 \\
\hline grade 3 & 2 & 1.12 & Total & 265 & 100.00 \\
\hline grade 4 & 2 & 1.12 & & & \\
\hline Total & 179 & 100.00 & & & \\
\hline
\end{tabular}

\section{Figures}




\section{Initial visual factor}

A. Initial visual acuity category
Raw points

$\mathrm{NLP}=60$

$\mathrm{LP}$ to $\mathrm{HM}=70$

$1 / 200$ to $19 / 200=80$

$20 / 200$ to $20 / 50=90$

$\geq 20 / 40=100$

B. Globe rupture

$-23$

C. Endophthalmitis

$-17$

D. Perforating Injury

$-14$

E. Retinal detachment

$-11$

F. Afferent pupillary defect

\section{Probability of visual outcome}

\begin{tabular}{|c|c|c|c|c|c|c|}
\hline $\begin{array}{l}\text { Raw } \\
\text { score sum }\end{array}$ & $\begin{array}{l}\text { OTS-Score } \\
\text { category }\end{array}$ & NLP (\%) & $\begin{array}{l}\text { LP/HM } \\
(\%)\end{array}$ & $\begin{array}{l}1 / 200-19 / \\
200(\%)\end{array}$ & $\begin{array}{l}20 / 200-20 / \\
50(\%)\end{array}$ & $\begin{array}{l}\geq 20 / \\
40(\%)\end{array}$ \\
\hline $0-44$ & 1 & 73 & 17 & 7 & 2 & 1 \\
\hline $45-65$ & 2 & 28 & 26 & 18 & 13 & 15 \\
\hline $66-80$ & 3 & 2 & 11 & 15 & 28 & 44 \\
\hline $81-91$ & 4 & 1 & 2 & 2 & 21 & 74 \\
\hline $92-100$ & 5 & 0 & 1 & 2 & 5 & 92 \\
\hline
\end{tabular}

HM, hand movements; LP, light perception; NLP, no light perception; OTS, Ocular Trauma Score.

Figure 1

Calculation of the OTS 


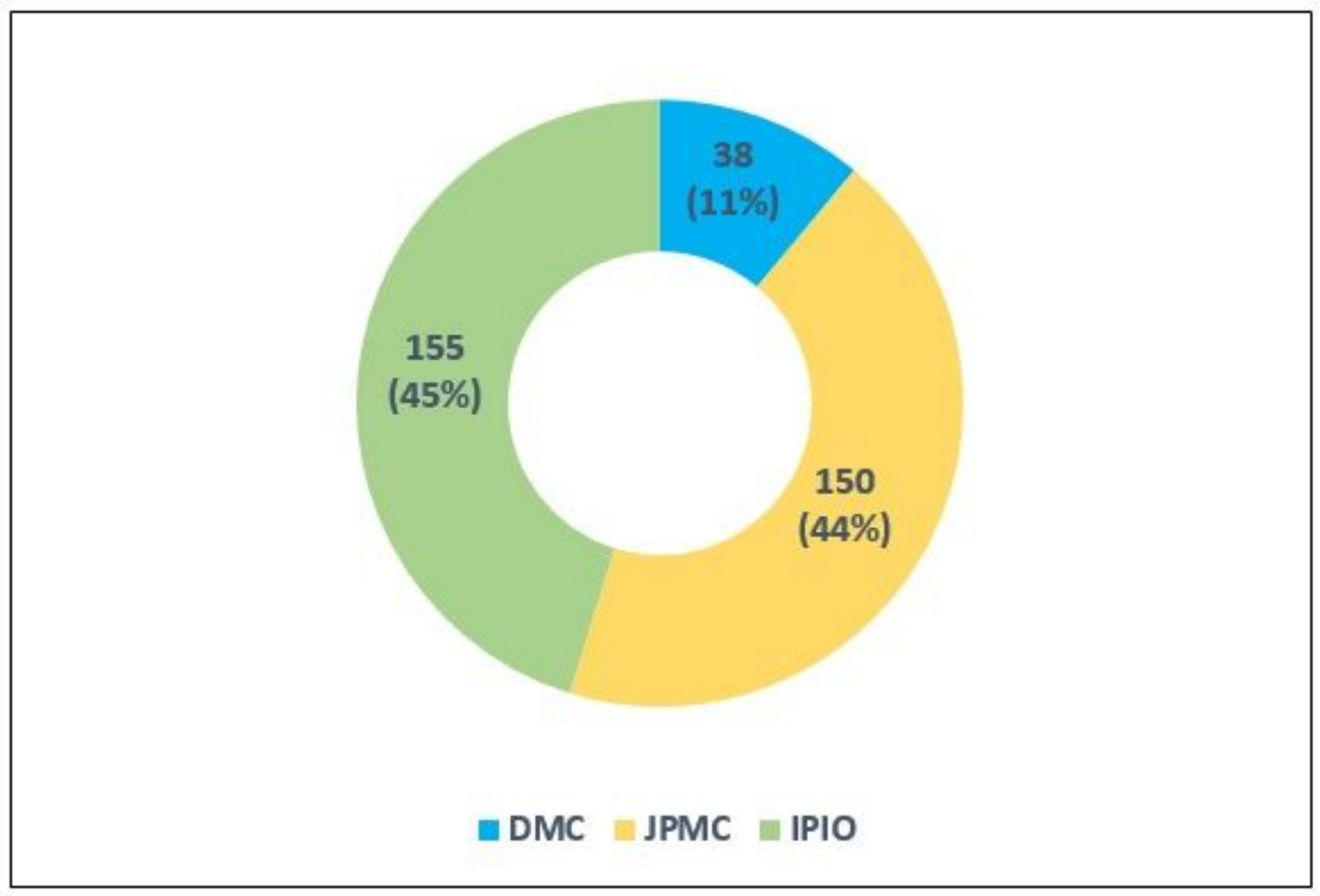

Figure 2

Patients presenting at each centre

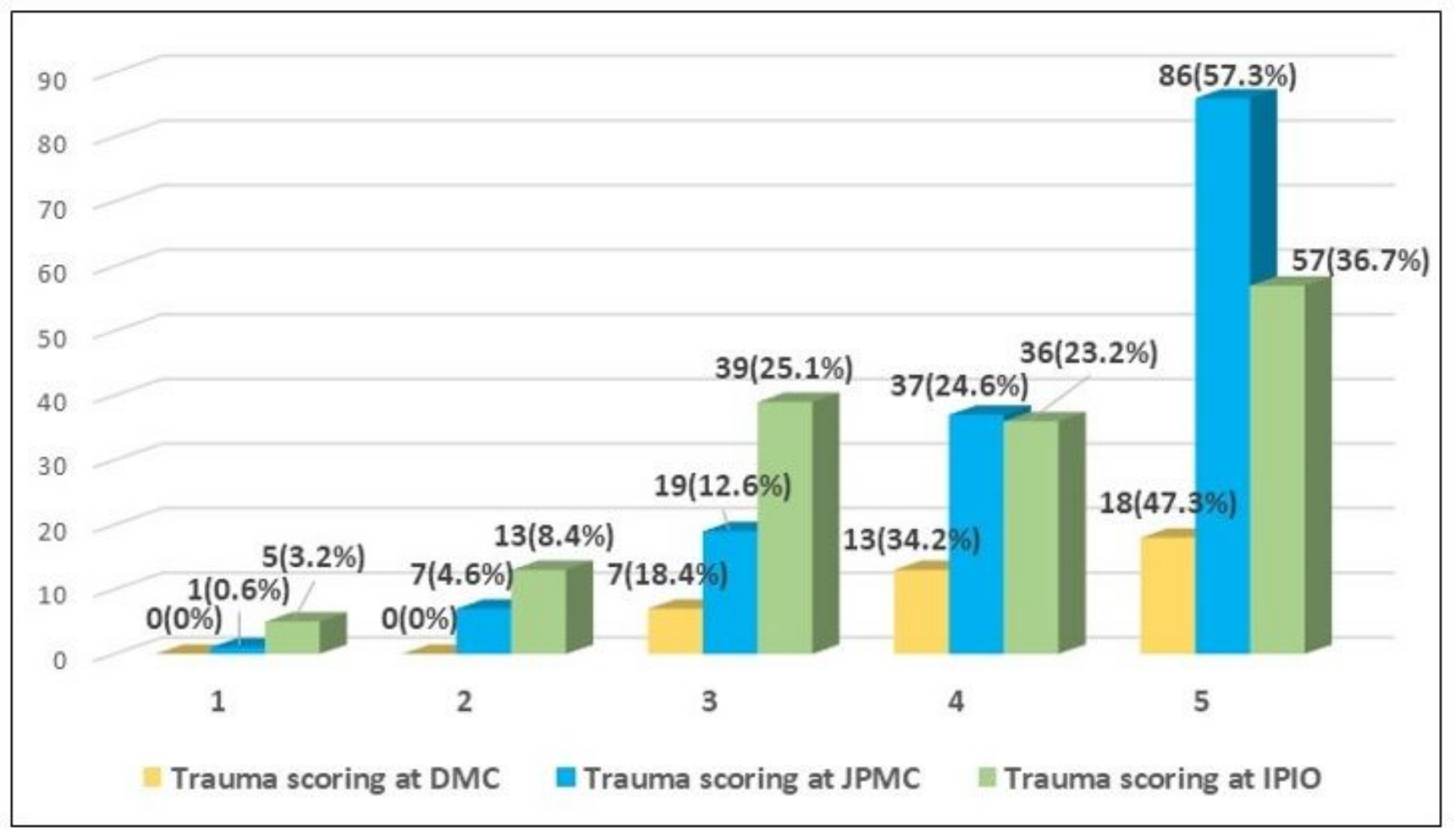

\section{Figure 3}

Trauma Scoring at three tertiary centres 